\title{
De sogra para nora para sogra: redes de comércio e de família em Moçambique
}

\author{
Marta Jardim**
}

\begin{abstract}
Resumo
Levando em conta a perspectiva histórica, examino, neste artigo, a relação entre uma nora e uma sogra hindu numa rede migratória que envolve Diu - Índia, Moçambique, Portugal e Inglaterra. Esta reflexão faz parte de uma pesquisa sobre a família hindu em Moçambique, estabelecendo um diálogo crítico com estudos que analisam a família hindu como o lugar de reserva das marcas identitárias das populações às quais se atribui origem indiana em África. Inspirada na literatura antropológica, que enfatiza a relação entre os sistemas de relação $e$ o tempo, procuro destacar a flexibilidade das hierarquias das quais participam as mulheres casadas indianas no contexto contemporâneo de Moçambique.
\end{abstract}

Palauras-chave: Etnografia, Família, Hindus, Moçambique, Sograria.

\footnotetext{
* Recebido para publicação em maio de 2007, aceito em agosto de 2007.

*** Bolsista Fapesp de Pós-Doutorado no CEBRAP. martabane@gmail.com
} 
De sogra para nora para sogra

From Mother in Law to Daughter in Law To Mother in Law

On commercial and Family Networks in Mozambique

\begin{abstract}
Taking into account the historical perspective, I examine in this article the relation between a Hindu mother-in-law and her daughter-in-law within a migration network involving Diu (India), Mozambique, Portugal and England. My reflections are part of a research project on Hindu families in Mozambique, aimed at establishing a critical dialogue with those studies that see the Hindu family in Africa as a stronghold of identity for populations thought of as originally Indian. Inspired in the anthropological literature that emphasizes the time dimension of relational systems, I seek to underline, in the context of contemporary Mozambique, the flexibility of hierarchies in which married Indian women participate.
\end{abstract}

Key Words: Ethnography, Family, Hindus, Mozambique, Sograria. 
Marta Jardim

\section{Introdução}

Senhora Madhabe (nascida, residente e formada no secundário em uma cidade sul moçambicana, 39 anos e lojista) mostrou-me seu caderno de sogra. ${ }^{1}$ Em uma brochura, cuja capa exibia uma propaganda da Frente de Libertação de Moçambique - FRELIMO - sobre o programa de alfabetização dos anos 80, ela registrava, em gujarati - uma das 22 línguas oficiais da Índia diversas anotações. Neste caderno, encontrei registros de materiais utilizados no ritual de adoração da vaquinha - (que narra) a história de uma sogra e de uma nora -; croquis indicando o lugar dos materiais utilizados em outra cerimônia em agradecimento à deusa mãe por ter recebido filhos homens; letras de músicas; versos e um pequeno glossário gujarati-português e gujarati-inglês para produtos usados em rituais e produtos comestíveis.

Nem todas as senhoras, às quais se atribui $e$ que se reconhecem de origem indiana, que acompanhei em Moçambique possuem cadernos de sogra. Mas estas $e$ as que se reconhecem como autóctones de Moçambique estabeleceram relações de sograria. Em minha tese encontrei na expressão sograria - termo de uso comum aos moradores de cidades sul moçambicanas, indianos ou não - uma possibilidade de abordar a história da família indiana em suas relações com o contexto migratório. De modo que, explorando práticas que dão significado à sograria, me oponho às análises que compreendem a família indiana pela via

1 Este artigo dá continuidade às reflexões iniciadas em meu doutorado (Jardim, 2006). Para realização da tese morei durante um ano na cidade de Inhambane, na região sul de Moçambique, entre março de 2003 e fevereiro de 2004. A pesquisa de campo foi mantida pelo programa PDEII da CAPES e teve apoio, no Brasil, da Unicamp e do Cebrap e, em Moçambique, do Centro de Estudos Africanos da Universidade Eduardo Mondlane. Esta pesquisa está inserida num projeto coordenado por Omar Ribeiro Thomaz, que investiga as implicações da "oposição forasteiro x nativo" em diferentes contextos pós-coloniais (Thomaz, 2001; 2004). As expressões êmicas aparecem em itálico. 
De sogra para nora para sogra

do isolamento em contexto africano (Rita-Ferreira, 1984; Prunier, 1990).

Ainda descrevendo as relações nas sograrias de mulheres casadas, foco o processo no qual uma nora passa a ocupar o lugar de sogra. A descrição que proponho em um ciclo anelar - deixar os pais e fazer crescer os filhos e fazer casar o filho homem permite pôr em suspeita as caracterizações correntes sobre mulheres casadas de origem indiana. Também inspirada nos estudos de classe, de idade (Seeger, 1980; Maybury Lewis, 1984; Debert, 1998; Geffray, 2000), procuro fornecer um modelo que ilumine as possibilidades estruturalmente ofertadas às mulheres casadas na sua travessia da posição de nora para sogra.

A partir da noção inaugurada em Fortes (1970), na década de 40 , a respeito do tempo como fator explicativo nos estudos de família e parentesco, resgato, de Veena Das (1998:38), a noção de "sentido de pretérito composto, continuamente recomposto". A autora valoriza este sentido na análise de narrativas que dão conta de conflitos - de sexo e geração - expressos no quotidiano familiar.

Baseada nestes estudos, pretendo descrever a flexibilidade das hierarquias das quais participam noras e sogras. Esta flexibilidade é especialmente notada na articulação entre as práticas familiares e o contexto migratório, que tem em Moçambique um dos seus eixos seculares. Levando em consideração as críticas produzidas, no pensamento antropológico, em torno aos lugares ocupados pelos recortes Índia (Das, 1995; Herzfeld, 2001) e família (Goody, 1998; Bestard, 1998), recupero o aspecto processual que essas categorias podem evocar.

\section{Castas ou sograrias?}

No sul de Moçambique, em especial na cidade de Inhambane, observei o uso da palavra sograria (em português) no contexto de fala de três línguas autóctones e em gujarati, embora 
existam expressões equivalentes nestas quatro línguas. ${ }^{2}$ Não tendo encontrado referências bibliográficas para a palavra sograria, aceitei, provisoriamente, a caracterização oferecida em uma monografia etnográfica bantu para a "vukon wana" como o lugar $e$ o laço que une um homem tsonga à sua família de aliança (Junod, 1996). ${ }^{3}$

Partindo desta noção, apresento três situações organizadas com base em meu trabalho de campo. Quatro fontes interdependentes organizam essas situações: a observação informal de rotinas nas cozinhas; uma coleção de histórias de casamento; a opinião de não indianos sobre minha pesquisa $e$ a literatura sobre a presença indiana na África, no que diz respeito à família.

Durante o ano que morei em Inhambane, acompanhei sistematicamente a rotina das cozinhas das residências, observando a relação nora e sogra. ${ }^{4}$ Tal estratégia de pesquisa me ofereceu dados informais em palavras, gestos, atitudes $e$ comportamentos sobre esta relação. Por outro lado, nos últimos

\footnotetext{
${ }^{2} \mathrm{Na}$ cidade de Inhambane (com aproximadamente 50 mil habitantes) estão estabelecidas em torno de 50 residências de professantes do hinduismo, migrantes e descendentes de indianos oriundos de Diu - um dos três territórios indianos que compuseram o Estado da Índia Portuguesa entre o século XVI e 1962 - localizado no Estado do Gujarate (centro da Índia), que tem como língua principal o gujarati. Em Inhambane, as populações de origem indiana falam gujarati, português, xitsonga, gitonga, cicopi, xironga, xichangana, inglês. Nesta cidade, todos os indianos hindus são comerciantes (de 50 casos, 48 são proprietários e dois empregados do comércio).

${ }^{3}$ Para Junod, a palavra vengui é utilizada por uma mulher casada para tratar o irmão mais velho de seu marido. É um termo recíproco. Este termo me foi traduzido como sograria em Ronga, na região de Maputo.

4 Ao acompanhar, sobretudo, o cotidiano das senhoras casadas, nas unidades domésticas notei a rotineira referência à sogra de uma mulher casada. Morando na mesma unidade doméstica da sogra ou em unidade separada (que pode estar no mesmo país ou não), as senhoras casadas explicam suas atitudes por referência às suas sograrias, suas sogras e cunhadas. A relação de um homem casado com sua sograria está sendo objeto atual da Pesquisa de Pós-Doc.
} 
De sogra para nora para sogra

quatro meses de campo, a partir de uma coleção de histórias de casamento, formulei padrões ideais da vida de casado.

A terceira fonte de dados resulta dos diálogos estabelecidos com não indianos sobre minha pesquisa. Correntemente, ouvi exemplos que ilustravam a noção de que as mulheres casadas indianas estavam fadadas a uma vida de submissão, primeiro aos desígnios do pai, depois aos do marido e da sograria (sogros, cunhado e esposa). Essa noção é compartilhada por autores que tratam da presença indiana em contexto africano (Rita-Ferreira, 1984; Teixeira, 2000), ao investigar, prioritariamente, as relações das populações de origem indiana com o Estado (colonial e póscolonial). Mas é na associação entre a rede familiar e o sistema de castas que identificam as causas do suposto isolamento dessas populações. A associação entre família e o sistema de castas é trazida como a natureza mais profunda das populações de origem indiana. No único estudo dessas populações, enfatizando a família e o contexto migratório, Kuper (1961) argumenta que, embora o sistema de castas não se reproduza na complexa sociedade sulafricana, ele sobrevive com a reprodução das práticas endogâmicas.

As histórias que apresento estão organizadas de forma a não se encaixar neste estereótipo. Para isso, levo em consideração os debates que, mesmo na Índia, contestam o sistema de castas como chave explicativa determinante (Leach, 1969; Srinivas, 1970; Marriot, 1976; Perez, 1994). Recupero as reflexões que mostram a historicidade da categoria e sua relação com o sistema administrativo colonial inglês que a generalizou para todo o subcontinente (Weber, 1987; Raheja, 1988; Dumont; 1992; Perez, 1994). Também levo em conta, de um lado, a revisão crítica de Dumont aos estudos sobre o sistema de castas na Índia até os anos 60 e, de outro, a defesa de Dumont de que não é possível aceitar a casta como categoria isolada, sem o sistema, quando fora do contexto indiano. Finalmente, considero os movimentos teóricos realizados em estudos de diáspora indiana (Vertovec, 2000; Bastos, 2001). Embora não seja foco de minha análise, a reflexão 
crítica sobre a relação entre a família indiana e o sistema de castas subjaz meu olhar, privilegiando a observação de práticas que não têm relevância exclusiva para populações a que se atribui origem indiana em contexto africano.

Observando aspectos que afirmam relações de sograria de uma mulher casada indiana, apresento três histórias. Essas histórias deixam ver, ao menos três momentos da travessia norasogra e, com isso, destaco posições distintas que mulheres casadas ocupam nos jogos hierárquicos que constituem suas sograrias. As histórias também ilustram a conexão (e não o isolamento) da constituição dos laços familiares com processos históricos $e$ políticos estabelecida por essas populações no contexto migratório com os quais se relacionam (Índia, Moçambique, Portugal $e$ Inglaterra). $\mathrm{O}$ esquema cíclico apresentado pretende dar visibilidade a uma espécie de arranjo para construir a hipótese de que, olhando para as práticas, mesmo das "famílias indianas" recorte que congrega dois ícones da tradição (família e Índia) - se pode explorar dinâmicas que se articulam aos processos contemporâneos mais amplos.

\section{Mimos entre Homoíne e Lisboa: na altura de meter pedido}

Jagrati Mamprassad Locknat - nascida e residente na cidade de Inhambane, com 19 anos, tendo concluído a escola secundária e realizando um curso particular de computação e inglês - aceitara pedido de casamento metido pela Casa Badrinath. ${ }^{5}$ Kabir

\footnotetext{
${ }^{5}$ Utilizo Casa em maiúsculo para indicar um domínio que articula e organiza práticas de cozinhar, adorar (ritualizar) e fazer negócios. Uma Casa pode congregar diferentes unidades domésticas e negócios que podem estar em diferentes territórios nacionais. Uma Casa também pode ser explicada como a representante viva do domínio de uma linhagem, o gotra. Assim, enquanto o gotra reúne todos os descendentes, vivos ou mortos, de um homem e sua correspondente prática de adoração, a Casa reúne apenas os vivos, atuando em comunicação com seus mortos. Diferente da Casa e do gotra, a sograria relaciona exclusivamente homens e mulheres (uma vez) casados. Sendo assim, os miúdos e solteiros não fazem parte de qualquer sograria, embora integrem
} 
De sogra para nora para sogra

Baghava Badrinath, o pretendente - nascido em Moçambique e atual residente de Lisboa, 23 anos, formado na escola básica -, era funcionário de uma empresa de turismo. O anúncio do anelado, em Inhambane, se deu numa terça-feira de setembro de 2003, quando, no arti da Casa Badrinath, a Senhora Amrit, viúva do irmão do pai de Kabir, levou Jagrati para conduzir a lamparina em oferta às divindades. ${ }^{6}$ Mas, já em fevereiro de 2004, os rumores sobre o fim do anelado sugeriam que a Casa Badrinath não recepcionara adequadamente a futura nora, fazendo com que a Casa Locknat estivesse reavaliando o pedido anteriormente aceito.

Voltar atrás em um pedido de casamento já aceito é considerado bastante desonroso para ambas as Casas envolvidas. Desde o momento em que se publica o anelado, uma série de constrangimentos favorece relações pretensamente simétricas entre as duas Casas. ${ }^{7}$ Escolheram-se e, no período do anelado, afirmaram as razões da escolha. As práticas e comentários positivam a Casa do pretendente e a Casa escolhida. Os custos simbólicos e econômicos do rompimento de um anelado atingem não apenas os membros do casal, tampouco exclusivamente seus

Casas e gotras. A sograria também não pode ser pensada como um desdobramento do gotra e da Casa, porque enquanto estes dois domínios são patrimônio apenas da linha paterna, a sograria é um domínio diferente para o homem e para a mulher.

${ }^{6}$ Arti é o nome de um ritual que ocorre diariamente nas unidades domésticas e na Comunidade Hindu de Inhambane. As senhoras da diretoria desta Comunidade organizam uma lista que indica o dia que cada Casa se responsabiliza pela realização do ritual na sede da Comunidade. No ritual da Comunidade as Casas podem anunciar acontecimentos, como anelados $e$ casamentos.

7 Quando duas Casas concordam em fazer casar seus filhos, os pais tornam-se compadres. Quando esse compromisso é anunciado, as tratativas mais íntimas já acontecem. Tais tratativas partem da identificação dos gotras impedidos de troca e de gotras com quem se possui tradição de troca matrimonial. Envolvem, em cada Casa, os mais velhos (pais, avós, sogros) e os contemporâneos aos noivos (irmãos já casados, cunhadas). 
Marta Jardim

pais em suas respectivas residências, mas também - ainda que de forma diferenciada - o conjunto de laços que afirma nomes de Casas e gotras. ${ }^{8}$

Não acompanhei o final do episódio sobre o casamento de Jagrati e, portanto, não sei se os desgostos da relação nora e sogra teriam sido suficientes para desfazer o anelado. Mas os rumores, neste caso, indicavam que, na relação entre as futuras nora $e$ sogra, se pode avaliar a aliança. A relação nora e sogra, que pode ser considerada como tensa, depois que a miúda vai viver para sua sograria, e como apaziguada, depois que a sogra envelhece, no anelado costuma ser amistosa.

$\mathrm{O}$ anelado, diferente sobretudo do momento posterior à cerimônia de casamento e antes do nascimento do primeiro filho, é concebido como um momento pacífico e agradável da relação. Narrativas de episódios desagradáveis durante o anelado podem servir de base - sempre a posteriori - para explicar relações rompidas no anelado ou no casamento ${ }^{9}$ e são reinterpretadas como sinais de que algo não iria dar certo.

As narrativas sobre o período dos anelados que resultaram em matrimônios descrevem momentos considerados pitorescos $e$ engraçados da relação nora e sogra - os desentendimentos aparecem como situações sobre as quais se deve rir. Idealmente, se toma o anelado como um momento de mimos. Enquanto nora anelada, nomeada miúda, uma mulher olha para a residência do

\footnotetext{
8 Embora a Casa possa ser pensada como um desdobramento vivo do gotra, levo em conta o que Bourdieu afirma caracterizando o parentesco prático, entre a tensão, relativismo, objetivismo. Para o autor é preciso ter em conta que "as relações entre ascendentes e descendentes não existem se não ao preço incessante de tecê-las por meio de uma economia das trocas materiais e simbólicas entre gerações" (Bourdieu, 1980:280). Assim, as Casas, bem como os gotras, resultam de práticas constituídas pelas unidades domésticas que efetivamente participam do jogo político de sua afirmação.

${ }^{9}$ Nas histórias de casamento, os rompimentos ou não aceitação de pedidos só são relatados quando outros pedidos mais promissores foram aceitos. Mas, nas observações informais do cotidiano das cozinhas, essas histórias de rompimento - inclusive outras tantas histórias que normalmente não aparecem - são trazidas.
} 
De sogra para nora para sogra

futuro marido como um espaço novo, no qual vê problemas semelhantes aos da residência de seus pais, mas que são resolvidos de forma diferente.

A Casa da noiva recebe as novidades da Casa do noivo com simpatia e há uma tentativa explícita de buscar uma comunicação mútua, que passa pelo leva-e-traz articulado pelas duas Casas. A sogra elogia a nora, elege-a para representar a Casa em ações rituais de destaque, como aconteceu com Jagrati. Para tanto, lhe oferece saris e enfeites. Leva-a para passeios e para fazer compras e também a enfeita nessas ocasiões. Pede sua ajuda para organizar e preparar almoços, pedindo-lhe que execute atividades semelhantes àquelas que executa junto de sua mãe, como colocar a mesa e preparar colares de flores. Traz a nora para a loja para auxiliar, sem sobrecarregá-la.

No entanto, como os sogros residiam em Lisboa no período de seu anelado, Jagrati foi recebida na Casa Badrinath pela viúva do irmão do pai de seu pretendente. Na residência desta viúva, seu filho e nora, ainda sem bebê, os pais de Jagrati foram recebidos para a contratação do anelado. Por meio das mãos da viúva Amrit, Jagrati foi presenteada com roupas, bijuterias, jóias, sapatos e perfumes. Amrit e sua nora vestiram e maquiaram Jagrati para que representasse a Casa Badrinath no arti, que aconteceu no mês do anelado.

Situação como a de Jagrati, recebida por uma espécie de sograria substituta, não é excepcional. Além de várias histórias com sogros já falecidos, outras tantas ilustram o fato dessas pessoas estarem organizadas, há pelo menos um século, numa rede de migração que envolve Índia, Moçambique (e outros países africanos, como o Quênia, Tanzânia, Uganda, Malawi, África do Sul), além de Portugal e Inglaterra (e, mais recentemente, outros países europeus, como a Espanha, e países latinoamericanos, como a Venezuela).

Se a sograria indica o laço e o lugar que une um homem ou mulher à sua família de aliança, no caso destas populações, que estão articulando redes migratórias, o lugar da sograria está difuso. 
Não se trata de imprecisão, as moças em idade de noivar conhecem as possibilidades de que podem lançar mão. Quando uma Casa está selecionando moças para meter pedido, ou avaliando pedidos recebidos, considera diferentes aspectos: o lugar onde o novo casal vai se instalar, os empreendimentos econômicos, os gostos, a posição social.

Numa tarde de outubro ouvia Jagrati Mamprassad Locknath e a filha da irmã de seu pai, Shapahula Maitri, compararem a relação de ambas com suas sogras, ou melhor, com suas futuras sograrias. Shapahula, também nascida em Inhambane, da mesma idade e formação de Jagrati, e já tendo concluído o curso de computação, está anelada com Birendra Chaytania, filho de vizinho da Casa do pai de Shapahula na cidade de Inhambane. Mas o noivo de Shalpahula está com 26 anos e controla e administra, toda a semana, a loja de seu pai no interior da Província de Inhambane.

A sograria de Shapahula é ao lado da Casa de seu pai. A sograria de Jagrati é em Lisboa e tem pessoas que a representam na cidade de Inhambane. Shapahula mostra o último sari que ganhou, que usará para acompanhar os sogros em um casamento no norte de Moçambique em duas semanas. Este sari é apenas para o dia da viagem. Num saco, outros dez saris serão exibidos. Shapahula explica o uso de cada um de acordo com a orientação recebida da sogra: durante a viagem, na chegada na cidade da cerimônia, um para cada um dos quatro dias cerimoniais, e outros quatro para serem usados nas diferentes atividades dos dias cerimoniais.

Jagrati considera os modelos de sari de Shapahula um pouco ultrapassados. Compara-os àqueles que seus sogros the enviaram de Lisboa. Lembra que os saris tinham sido comprados na Índia pelos os sogros no início de 2003. Acompanhavam os modelos de sari utilizados por algumas das atrizes-intérpretes musicais mais ovacionadas dos canais indianos assistidos em Inhambane naquele ano. 
De sogra para nora para sogra

Embora se sinta contemplada com presentes superiores ao de Shapahula, Jagrati verbaliza queixas à sua sograria em tom jocoso. Comenta a pressão da sograria para que sua família compre os materiais para a cerimônia de casamento. Questiona as razões dos sogros para não fazerem estas compras em Lisboa, onde, em sua opinião, há mais variedade de produtos e preços. Também considera que, uma vez que os sogros foram à Índia, deveriam ter vindo até Inhambane no mesmo período. Jagrati queixa-se dos sogros não terem ido diretamente meter pedido aos seus pais. A queixa é anunciada imitando palavras e gestos feitos por sua sograria de Inhambane. Rindo de sua própria imitação, Jagrati substitui as palavras de Amrit e de seu filho, que falavam em nome da Casa Badrinath, especialmente de Baghav Badrinath, pai do pretendente, por palavras diretamente ditas por Baghav. Shapahula dá risadas o tempo inteiro. Elas me olham convidando-me a rir junto.

A cena engraçada não desmerecia a sograria de Jagrati, que mostrava orgulho de ter um noivo cuja unidade doméstica dava sinais de estar bem estabelecida em Lisboa. $\mathrm{O}$ irmão mais velho $e$ o pai de seu noivo (Kabir) possuíam uma espécie de franquia que lhes permitia vender produtos, como shampoo, papéis para cigarros, pilhas, etc. Moravam em um flat no subúrbio de Lisboa, no mesmo bairro do estabelecimento. A renda da unidade era mantida pelo emprego de Kabir em uma agência de viagem que favorecia idas de sua família para Londres e Índia, aspecto sempre lembrado ao comentar o emprego dele.

Embora direcionando sua vida de casada para o interior moçambicano, Shapahula não se mostrava humilhada frente ao destino de Jagrati. A unidade doméstica dos seus sogros tinha duas lojas, uma delas com direito exclusivo de comercializar medicação. Shapahula moraria com o marido na unidade doméstica onde está a loja, ou seja, em unidade doméstica distinta de sua sogra e, ainda por cima, dando conta do comércio mais promissor de sua sograria. Também Birendra é o único filho homem. Já Jagrati casaria com um segundo filho homem e 
moraria com a própria sogra, o cunhado mais velho e sua esposa em país distinto da unidade doméstica de seu pai. Ao contrário de Birendra, que possuía o direito de comércio em dois pontos estrategicamente importantes em Moçambique, Kabir era empregado e auxiliava o pai e o irmão mais velho para compor a renda da residência em Lisboa.

Estar numa esquina entre o interior moçambicano e uma capital européia é situação recorrente nas histórias de casamentos que ouvi. A distância não é necessariamente considerada um fator de vulnerabilidade para uma nora, uma vez que, na nova cidade ou país, irá encontrar tanto pessoas relacionadas à sua sograria, quanto pessoas relacionadas à Casa de seus pais. Desde Motibai primeira mulher de origem indiana a chegar em Inhambane em 1923 - até os dias atuais, a rede de migração aberta pelos homens se ampliou, desdobrando-se na organização de unidades domésticas e espaços rituais em continentes distintos. Se, até a virada do século XIX para o XX, as famílias hindus se reproduziam na Índia graças ao trabalho migratório masculino, a partir da migração das mulheres para África, a reprodução familiar passa a se dar em diferentes territórios. ${ }^{10}$

\footnotetext{
${ }^{10}$ A literatura histórica indica que a presença de populações de origem indiana em migração masculina - na África oriental é mais antiga do que a européia (Curtin, 1986; Pereira Leite, 1996; Newit, 1997; Alencastro, 2000). Para o contexto moçambicano - e diferente do contexto angolano (Galvão, 1957) - os indianos são indicados como os responsáveis pela articulação entre o interior e o mercado internacional europeu durante o século XVII (Pereira Leite, 1996). Indica-se também que, através do uso das línguas locais e de alianças matrimoniais (lobolo), homens indianos, muçulmanos e hindus constituíram essa rede (Pereira Leite, 1996; Zamparoni, 1998; Teixeira, 2000). Embora a migração fosse masculina o seu motor era familiar. Os indianos são indicados na mesma literatura como uma população que não se fixava na África, apenas fazia negócios que alimentavam suas famílias na origem. A chegada das mulheres indianas em Moçambique coincide com a chegada de mulheres de outras nacionalidades (Zamparoni, 1998; Teixeira, 2000). O aumento do número de mulheres está relacionado à constituição do Estado Colonial Português entre 1890-1974.
} 
De sogra para nora para sogra

O domínio moral da sograria submete as unidades domésticas a ela relacionadas e aparece como um elemento tradicionalmente incorporado nas histórias de casamento de senhoras que se reconhecem de origem indiana em Moçambique. Observando o período mais longo da relação nora-sogra percebese como as implicações deste domínio participam dos jogos hierárquicos depois do anelado.

Tensões de Cumbana a Londres: da despedida da miúda e do fazer crescer os filhos

Passados os quatro dias da cerimônia de casamento, chega a hora da Casa do sogro deslocar-se até a residência dos pais da miúda para buscá-la. Deste dia em diante, esta não será mais considerada uma miúda. Neste dia, ela se despede de sua Casa para passar a integrar a Casa de seu sogro. A cena, de dar nó na garganta, mostra uma mulher em prantos. Abraçados a ela, mãe, pai, irmãos e irmãs (mesmo casados) choram copiosamente. Todas as senhoras casadas que acompanham o cortejo lembram o dia em que se despediram de seus pais e relatam o evento banhado de lágrimas. Mesmo a mãe do noivo, que está recebendo a nora em sua Casa, chora lembrando-se de sua despedida. ${ }^{11}$

Ao deixar de viver com seus pais e passar a residir numa das unidades domésticas de sua sograria, a mulher se transforma em nora e transforma a mãe de seu esposo, que era nora, em sogra. Esta mulher recentemente transformada em sogra pode continuar nora de outra mulher, sua sogra grande. Várias cerimônias - feitas

\footnotetext{
${ }^{11}$ Encontrei em Junod (1996) uma comparação entre as mulheres de origem indiana (antigo povo ariano) e as mulheres tsongas no que diz respeito às suas solidariedades com as respectivas famílias consanguineas. De seu ponto de vista, as indianas rompem definitivamente com essas solidariedades, enquanto as tsonga as mantêm indiretamente. Em minhas observações de campo não confirmei a hipótese de Junod para as mulheres indianas contemporâneas fora da Índia. Práticas rotineiras afirmam as redes uxorilaterais sem colocar em risco o valor da linhagem paterna.
} 
em nome da tradição da Casa e do gotra - são realizadas nos primeiros tempos, que podem ser dias, semanas, meses ou anos, $e$ que encerram assim que a nora estiver de bebê.

Diferente do período do anelado, este, de ingresso em residência da sograria, é lembrado como difícil. Nora e sogra percebem as diferenças na forma de resolver problemas comuns. Ambas olham com antipatia para essas diferenças. O limpo e o sujo são conteúdos dessas observações. Sogras reclamam que noras não sabem cuidar das roupas: não sabem lavá-las, ou não as lavam na periodicidade adequada. Noras suspeitam das louças lavadas pelas sogras. Noras falam da repugnância com que comem algumas comidas da sogra. Sogras exigem das noras que se apresentem sempre mais limpas para que possam tocar em qualquer alimento a ser preparado.

Esse momento é experimentado e narrado como crítico e tenso, tanto para a nora quanto para a sogra, embora seja evidente a posição mais vulnerável da nora. ${ }^{12} \mathrm{Em}$ termos ideais, essa vulnerabilidade na unidade doméstica - de domínio de sua sogra - vai sendo substituída por um gradativo equilíbrio de forças, culminando no nascimento do primeiro filho, em especial do filho homem.

Até este momento, nora e sogra têm claro a autoridade da sogra, pois ela está imbuída da tradição legítima do cozinhar, do adorar e do fazer negócio. A nora deve aprender essa tradição e estar frente à sua sogra na condição de aprendiz. A sogra tem muito a dizer $e$ a nora tem muito a ouvir $e$ observar. Diferentemente do momento anterior, em que ambas estavam em prova e avaliando a possibilidade do casamento, a partir de campos morais legitimamente distintos, depois do casamento,

\footnotetext{
${ }^{12}$ Este período é atravessado com o apoio de uma série de histórias (narradas, encenadas, dançadas, apresentadas em novelas, seriados e filmes...), piadas $e$ jogos que oferecem repertórios para administrar a crise concebida e narrada como passageira. Situações de crise não passageiras ou que envolvam casos trágicos ou violentos são tomadas como excepcionais e relacionadas a doenças físicas.
} 
De sogra para nora para sogra

espera-se que a nora vá desmarcando sua diferença e aprendendo silenciosamente a ser o que sua sogra lhe ensinar.

Ainda que a passagem da miúda para nora e da nora para sogra, a título de modelo idealizado, configure um momento de tensão maior do que o período do anelado, no jogo hierárquico concreto, outros fatores participam da relação. Na história do casamento de Kahini com Harihara Sedeep nota-se a flexibilidade dos jogos hierárquicos na travessia de nora para sogra. Essa história também exibe como, no contexto moçambicano, as populações de origem indiana são incorporadas em jogos hierárquicos locais e como estes participam das histórias de casamento.

A senhora Kahini - 37 anos, nascida em Inhambane, formada nos quatro primeiros anos numa escola em Diu e com a segunda parte do curso básico em Moçambique, lojista - casou em 1983 com o segundo filho da Casa Sedeep, que possuía uma loja em Cumbana, interior da Província de Inhambane e um dos pontos fortes de recolha da castanha de caju. A unidade doméstica dos pais de Kahini Jaijo descendia da Casa de chamadores e possuía duas importantes lojas na cidade de Inhambane. ${ }^{13}$

De meados dos anos 60 até sua independência de Portugal, Moçambique foi o maior exportador de castanha de caju do mundo. Lojas localizadas no mato faziam negócios rentáveis, recebendo e acumulando o produto direto do coletor. A Casa Sedeep, embora resultado de um chamado da Casa Jaijo, havia construído um caminho independente graças às exportações de

\footnotetext{
${ }^{13}$ Os termos chamado-chamador dizem respeito às histórias de migração DiuInhambane. Chamador era um homem já estabelecido que chamava um outro homem. Quem chamava patrocinava a vinda do chamado, recebia passagens, estadia, uma muda de roupa por ano e um corte de cabelo e barba por mês. Seu salário era retido na mão do chamador que, após aproximadamente cinco anos, entregava ao chamado o montante. Com este salário, os homens voltavam a Diu para casar $e$, desde a virada do século XIX para o XX, começaram a trazer suas mulheres para viver na África.
} 
caju. Na década de 80 , este negócio de exportação enfrentou a concorrência do fortalecimento da Indústria Nacional do Descasque da Castanha que, impulsionada pela política nacionalista do governo socialista da FRELIMO, reordenou a rede de comércio (Pereira Leite, 2000).

Kahini foi viver no interior da Província de Inhambane em residência composta pelo sogro, sogra, cunhado mais velho $e$ esposa. A narrativa dos três primeiros anos sublinha o estranhamento pela diferença entre cidade e mato. Além dos temores relacionados à presença de animais selvagens, ela também se sentia mais desprotegida frente à explícita maioria autóctone. Kahini quase não fala da sua relação com a cunhada mais velha e sogra, mas diz que foi como a de todas as mulheres quando deixam a proteção paterna.

Em 1983 Kahini teve o primeiro filho, homem. No mesmo ano, o cunhado e cunhada mudaram-se com os filhos para Lisboa. Vata Seddep havia optado por ficar português e, ao contrário dos demais irmãos, aceitara os benefícios que os portugueses ofereciam àqueles que se mudavam para a metrópole. ${ }^{14}$ Instalado em Lisboa, ele recebeu financiamento para adquirir um flat na periferia da cidade, onde também obteve licença e financiamento para instalar um estabelecimento comercial.

Kahini conta que o nascimento de seu filho e a mudança dos cunhados para Lisboa modificaram muito sua situação. Até então, não tinha queixas de sua sograria, mas sentiu-se muito mais autônoma quando sua sogra resolveu acompanhar o filho

\footnotetext{
${ }^{14}$ No período da independência, as populações de origem indiana - que haviam sido excluídas do Estatuto do Indigenato que teve como foco as populações consideradas autóctones ao continente africano - tiveram de decidir se ficariam com a cidadania portuguesa ou moçambicana. Grande parte das pessoas que contatei em Inhambane e Maputo optou por ficar potugueses. É comum encontrar em uma Casa indivíduos com passaporte português, moçambicano $e$ indiano. Muitos dos que optaram por ficar português permaneceram em Moçambique como residentes estrangeiros.
} 
De sogra para nora para sogra

mais velho no primeiro ano de viagem. Em Cumbana, Kahini passou a responder pela residência que dividia com o sogro e o marido. Quando a sogra voltou, já no nascimento de sua segunda filha, dois anos depois, Kahini tinha mostrado sua capacidade de dar conta das responsabilidades de uma mulher adulta.

Mas o retorno da sogra também estava associado à possibilidade de se instalar loja e residência em Inhambane. Os episódios da guerra civil, que crescia no decorrer dos 80, constrangiam um movimento de refugiados de guerra para as cidades. A concorrência da Indústria Nacional do descasque da castanha $e$ as agruras da guerra - que fazia aumentar o consumo interno deste produto, por falta de outros alimentos - são apontados por historiadores (Pereira Leite, 2000) como agravantes para fazer decrescer o negócio com a castanha. Esse decréscimo, visto da loja da Casa Sedeep, era analisado como um condicionante para ir à Lisboa ou ao Inhambane, onde, nestes casos, a Casa tinha um imóvel .

A abertura da nova loja foi planejada junto com o casamento do irmão mais novo de Harirara. A idéia era abrir a nova loja em Inhambane com o novo casal e manter a loja do interior. Todavia, em 1986, o marido de Kahini e o sogro - em viagem a Maputo para abastecer a loja e adquirir produtos para o casamento de Harirara - foram assassinados, junto com todos os demais usuários dos carros e caminhões que formavam uma coluna sob proteção dos carros oficiais da FRELIMO.

Geffray, em estudo antropológico sobre as causas da guerra em Moçambique, sugere uma razão para que a população atacada nas estradas não fosse retida nos campos correspondentes a cada facção - como acontecia nos ataques ao mato -, mas, sim, fosse morta e tivesse os bens destruídos. O autor aponta a oposição mato-cidade como razão para explicar a destruição da coluna:

A coluna é uma parcela da sociedade urbana, uma fracção da cidade que circula móvel e vulnerável, numa estrada 
entre dois centros urbanos. A quase totalidade dos passageiros é constituída por pessoas das cidades e das vilas, ou então camponeses que dispõem de uma rede de contatos urbanos, surpreendidos precisamente na ocasião de uma das suas idas e vindas à cidade ou à vila. Estas pessoas pertencem às camadas da população cuja condição foi profundamente transformada no período colonial, são empregados, trabalhadores, comerciantes, artesãos, negociantes ocasionais empenhados em comércios triangulares e quadrangulares..., desempregados que vivem de pequenos trabalhos e de expedientes, esposas que visitam os sogros no campo, ou que regressam da visita com um saco de mandioca, famílias à procura dum primo que prosperou na cidade... São todos aqueles que vivem no seio ou nas margens das redes sociais urbanas nascidas da situação colonial, os que melhor se adaptaram após a independência à nova situação $e$ ao novo Estado, com o qual têm por vezes ligações mais ou menos diretas. Por outras palavras, os viajantes das colunas são pessoas cuja condição é o oposto da condição dos marginais do Estado colonial, que continuaram abandonadas pelo Estado independente e que entraram em dissidência contra esse Estado, colocando-se massivamente ao abrigo das armas da RENAMO (Geffray, 1991:153).

A explicação que Geffray dá ao ataque à coluna que culminava na morte dos seus ocupantes associa a coluna à cidade e o ataque à coluna a um ataque à cidade, feito pelo mato. Essa hipótese se contrapõe à tese corrente que aponta como causa da guerra civil, exclusivamente, a agressão estrangeira dos governos racistas sul-africano e rodesiano. A hipótese de Geffray, desagradável aos olhos frelimistas, é de que a guerra expressa uma oposição no interior do que se podia chamar de nação.

Para meu argumento interessa notar a relação entre a guerra civil e as estratégias de reprodução da rede migratória operada pelas populações de origem indiana. Incluídos na categoria de citadinos e comerciantes, essas populações foram 
De sogra para nora para sogra

englobadas no sistema classificatório acionado na guerra. Além disso, a morte de Harirara e de seu pai, Seddep, resultará numa reorganização das hierarquias entre as mulheres da Casa Seddep.

A viuvez de Kahini e de sua sogra provocou o adiamento do casamento do irmão mais jovem de Harihara. Kahini permaneceu no interior com seus dois filhos pequenos, a sogra e o cunhado mais jovem. O casamento, um ano depois, constitui nova unidade doméstica em Inhambane. Kahini e a sogra permanecem no interior por três anos. Após este período, o agravamento da guerra, o enfraquecimento do negócio no interior e o crescimento do negócio na cidade levam Kahini, seus dois filhos e sua sogra para a cidade de Inhambane, onde vão morar na residência já montada pelo cunhado mais jovem de Kahini e sua esposa. Kahini lembra este período como o pior de sua relação com a sograria. Ela verá a sogra ocupando o lugar da maior autoridade da sograria, como nunca antes lembra ter visto e conta que a sogra se alia com a cunhada mais jovem, em detrimento dela, "como seria legítimo" - como cunhada mais velha na unidade doméstica, devia ocupar o lugar de autoridade.

Kahini diz que seus filhos teriam sido prejudicados na escola, ela teria servido à cunhada e sogra como se fosse a cunhada mais jovem, entregou ofertas de porta em porta, deu recados, picou, cortou e descascou legumes, depenou frangos, limpou vísceras de cabritos e peixes. A volta de Kahini Harihara Sedeep para a cidade de Inhambane é lembrada como o único momento em que se sentiu "uma estrangeira na própria casa".

A história de Kahini não se enquadra em uma noção linear da passagem da posição de nora para a de sogra. Não tendo se sentido vulnerável logo que foi "viver para sua sograria", Kahini experimenta a posição de submissão frente à sua sogra $e$, marcadamente ultrajante, à sua cunhada mais jovem. Essa condição de fragilidade, que resulta da viuvez, da ascensão econômica e social rápida do irmão mais novo do marido e do fato da cunhada, em ascensão, sediar a unidade doméstica da Casa, segundo Kahini, não se mantém igual em 2003. 
Em meados dos anos 90, Kahini recebeu apoio econômico de seus irmãos mais jovens para abrir uma loja na cidade de Inhambane. O edifício da loja - como é bastante comum comportava espaço residencial e Kahini mudou-se para lá. Os irmãos de Kahini estavam já há oito anos na Europa. Haviam ido inicialmente para Lisboa com o benefício do Estado português pós-independência. Desde a constituição da Comunidade Européia, com seus passaportes portugueses, foram para Londres trabalhar em fábricas de salsichas e, acumulando o salário dessa atividade, financiaram um táxi e dois flats.

Receber apoio econômico da Casa dos pais pode ser considerado uma afronta para a sograria de uma mulher. Mas as viúvas de Casas com mais descendentes homens tendem a tolerar esta situação, como explica Kahini, ao narrar o apoio de sua sogra que, inclusive, morou com ela na nova residência. Kahini destaca que sua nova residência era muito precária, comparada àquela em que vivia com sua cunhada mais jovem. Havia apenas um quarto e sua sogra dormia no sofá da sala. Se a atitude da sogra explicitava a aceitação da sograria de Kahini ao apoio de seus irmãos, esta aceitação não sinalizava o rompimento de Kahini com a tradição de sua sograria.

Entre 1998 e 2001, Kahini dividiu sua pequena residência com os filhos e a sogra. A loja não fazia negócios espetaculares, nem perto do que vendia a loja do cunhado, mas permitia-lhe o sustento sem precisar de ajuda freqüente dos cunhados e dos irmãos. Em 2001, a sogra foi viver em Lisboa para ajudar a nora mais velha nos preparos do casamento de seu primeiro filho. Quando convivi com Kahini em 2003, ela se preparava para fechar a loja e mudar-se para Londres para viver com um de seus irmãos, onde já vivia, e a esperava, seu filho mais velho com os tios maternos. Ela levaria a filha mais jovem e trabalhariam para custear suas despesas.

Se, de um ponto de vista ideal, aceita-se que desde o momento em que a mulher vai para o domínio de sua sograria ela está numa posição de submissão frente à tradição dos pais do 
De sogra para nora para sogra

marido, nas histórias particulares, percebeu-se outros fatores que participam do jogo hierárquico de uma mulher casada em relação à sua sograria. No período do casamento desta mulher, combinado ao período de casamento dos irmãos do marido, o número de cunhadas, a posição ocupada entre as cunhadas, os negócios da Casa, as disputas políticas e territoriais por classificações e a idade dos demais irmãos são aspectos do repertório de histórias de casamento de mulheres de origem indiana em Moçambique.

\section{O privilégio de fazer casar o filho: entre Inhambane e Diu}

Em novembro de 2003 assisti às cerimônias de falecimento da sogra da senhora Laximi Locknath. Residente de Inhambane há 50 anos, senhora Laximi realizaria 13 dias de cerimônias em nome de sua sogra falecida e cremada em Diu. Todas as unidades domésticas vinculadas à Casa Locknath em Moçambique, Portugal, Inglaterra e Índia obedeceram o jejum acordado para a cerimônia. Acompanharam e auxiliaram diariamente Laximi todas as suas três noras residentes na Província de Inhambane. As duas filhas casadas de Laximi, que moram em Inhambane, assistiram as cerimônias.

A senhora Laximi havia residido com a sogra em três situações. A primeira ocasião foi no período dos dois primeiros anos de casada, em Diu, quando o marido a deixou, com a sogra $e$ o sogro, para continuar o trabalho como alfaiate em Moçambique. Entre os anos 40 e 70, a Casa Locknath teve uma promissora alfaiataria na Província de Inhambane e atendia, com exclusividade, as forças armadas da Administração Portuguesa. Como resultado da ascensão da alfaiataria, Laximi, já com dois, dos seis filhos, foi com o marido e a sogra para Moçambique. Neste período, a sogra coabitou com Laximi e o marido por três anos. Quando os filhos já haviam sido casados, Laximi foi viver com a sogra, já viúva, e o marido em Diu. Em 2000, Laximi e o marido, vivendo outra vez em Inhambane, foram a Diu visitar sua 
sograria. Nesta viagem, seu marido morre. Ao lado da sogra, Laximi crema o marido em Diu, faz as cerimônias e volta viúva para Inhambane.

A sogra de Laximi vivia na residência de sua própria sogra, já falecida, em Diu, sendo apoiada pela filha casada. Mas no seu falecimento, não foi a filha casada quem se ocupou da mãe $e$ organizou as cerimônias, e sim a senhora Laximi, a nora mais velha, entre as vivas. A cerimônia é sustentada idealmente por todas as unidades domésticas que se identificam como compondo a Casa Locknath. Efetivamente, foram os filhos homens de Laximi que sustentaram e que foram identificados no interior da Casa como os responsáveis pela efetivação, a contento, da cerimônia. ${ }^{15}$

Nos treze dias de cerimônia, senhora Laximi vestiu os saris brancos do luto, não saiu do interior da residência, organizou $e$ serviu quatro almoços na sua própria residência e um almoço na sede da Comunidade. Senhora Laximi, que já foi uma estranha do gotra de seu sogro e sogra, nestes treze dias era a principal peça de um intrincado cerimonial de adeus à sua sogra-grande.

Laximi ocupa a posição de uma mulher que já fez casar seus filhos, neste caso, quatro homens. A cerimônia que orquestrava despedia-se daquela que era a representante da geração anterior que seria sucedida pela sua. Embora viúva, Laximi, foi casada com o segundo filho homem da Casa Locknath. Em função disso, da situação econômica de seus filhos casados e com filhos e da autoridade religiosa que Laximi representa em Inhambane, ela herdaria da sogra, recentemente morta, o papel de autoridade máxima das três gerações vivas desta Casa.

Kuper observa que, no contexto sul-africano, as kutuns hindus obedeciam a uma hierarquia marcada por sexo e idade.

\footnotetext{
${ }^{15}$ Os nomes das Casas são (apelidos, qualificativos) atribuídos aos homens ou às lojas, por indianos e não indianos. Os nomes que conheci indicavam homens ou lojas vivas ou existentes nos últimos cem anos. Os processos de nomeação resultam de movimentos de autonomização que se desenvolvem em nome de laços familiares (no nível do gotra, da Casa, das unidades domésticas, das linhas uxorilocais, das redes de comércio).
} 
De sogra para nora para sogra

Organizados patrilinear e patrilocalmente, homens mais velhos possuem autoridade sobre homens e mulheres de seu grupo de idade. Por outro lado, esses homens estão também submetidos à autoridade de homens mais velhos e de mulheres da geração seniors (Kuper, 1961:98). Assim, casais mais velhos possuem autoridade sobre casais mais jovens, o que faz com que homens adultos devam explicação, obediência e reverência a homens e a mulheres mais velhas.

Nas situações que observei em Inhambane, essa hierarquia também está incorporada no casal. Assim, Laximi Locknath, aos 72 anos, assumia o apogeu da hierarquia em sua sograria, embora viúva. Mantendo-se com saúde física será chamada para tomar as decisões mais importantes da Casa de seu sogro, como a escolha de nomes para casamentos dos filhos e filhos de filhos, as estratégias migratórias associadas a essas escolhas, as estratégias comerciais e profissionais lançadas $e$ as organizações ritualistas que a Casa está comprometida.

No entanto, essa posição é tão efêmera quanto as anteriores. Além disso, está associada ao fato de que as noras já estão preparando os pedidos de casamento de seus filhos e, portanto, ingressando na experiência de abandonar o ser nora $e$ passar a ser sogra. A sogra grande, diferente da sogra recente, participa indiretamente da formação da segunda geração de noras. Tudo é feito em seu nome, um nome que sintetiza a tradição viva daquela sograria. Mas seu nome é usado mais do que ela própria o usa. A sogra grande vai sendo reservada das cenas que fazem emergir a nova sogra.

As palavras são da sogra recente, enquanto a sogra-grande tem poucas palavras, não porque é uma estrangeira, cuja opinião não deve ser levada em consideração, como a nora recente, mas porque se supõe que já tenha passado todas as palavras à sua nora (hoje sogra). A sogra-grande é contida em seus movimentos, enquanto a sogra-recente circula em todos os espaços, resolvendo problemas, endereçando soluções, propondo novos caminhos. Este momento da relação é narrado como trabalhoso para a sogra 
recente, mas repleto de cuidados e afeto desta para com a sogra grande. Acentua-se o apego desta última à primeira.

Sogra grande e sogra recente afirmam sua comunhão na tradição comum que ambas construíram, através dos filhos que deram parto, que fizeram crescer e fizeram casar. No cotidiano das cozinhas de mulheres casadas de origem indiana em cidades sul moçambicanas se nota jogos hierárquicos que configuram repertórios tradicionais continuamente reordenados.

\section{Considerações finais}

Grande parte das residências que visitei reservava uma parede para fotos da sograria. Não há fotos dos pais da esposa (nora), murais ou porta-retratos. Há apenas fotos do sogro e da sogra. Na foto da sograria de uma mulher aparecem o pai e a mãe de seu marido, a foto de sua sogra, uma ex-nora. A mulher que não tem foto sua na parede da residência onde mora, hoje, terá quando fizer casar seu filho. Essa noção de ciclo por onde passa a vida de uma mulher casada me foi sugerida pela literatura sobre classe de idade.

Acessei poucos estudos sobre nora e sogra. Na literatura sobre a Índia são recorrentes os estudos sobre a saúde da mulher que remetem a situações de maus tratos perpetrados pelas sogras às noras. ${ }^{16}$ O antropólogo indiano Shah (1998), em balanço sobre

16 "Nora e sogra" é o recorte de um problema social na Índia (entre outros, Velkloff e Adlakha, 1998; Panikar, Rodriguez, De Souza, 1992). Sobre hindus em diáspora, em uma análise de rituais femininos, S. Bastos (2001) caracteriza alguns aspectos das posições hierárquicas de noras e sogras. $\mathrm{Na}$ literatura brasileira, alguns artigos levantam problemas em psicologia (Chiapin e Wagner, 1998). Batista (2004), analisando romances em língua portuguesa, indica a ausência de estudos e pesquisas sobre as representações sobre a mulher-sogra em oposição aos estudos das representações sobre a mulher-mãe. O estudo de Batista indica a ausência da personagem mulher-sogra na produção de romances, identificando, neste campo, dois livros produzidos em língua portuguesa no final do século XIX: O Livro de uma Sogra, de Aluísio de Azevedo (1895) e A velha, de Fialho de Almeida (de nacionalidade portuguesa). O 
De sogra para nora para sogra

estudos sobre família na Índia, considera que pautas do movimento feminista teriam favorecido estudos centrados na oposição homem-mulher. A centralidade desta oposição parece ter obscurecido o interesse de investigar outras relações importantes como entre cunhadas e entre noras e sogras. ${ }^{17}$

Estudando classes de idade, encontrei pesquisas sobre a relação genro-sogra numa perspectiva processual. Seeger, estudando o velho surya (sulameríndios), observa como, em uma sociedade uxorilocal, ocorre a mudança de status de um homem que, na qualidade de genro, ingressa na casa de sua esposa ocupando o lugar mais baixo na hierarquia: "esta posição inferior vai mudando com o tempo, à medida que o homem gera mais filhos e consolida sua posição política" (Seeger, 1980:73). Seu próprio sogro envelhece e o genro casa seus filhos, tornando-se também sogro e passando a representar a casa da esposa:

seus sogros acabam morrendo e o homem, que se incorporou pelo casamento, torna-se o chefe masculino de sua própria residência. Embora o aumento de status seja gradual, um ponto crítico é atingido quando suas filhas se casam e ele se torna sogro de alguns rapazes que se incorporaram pelo casamento, que devem mostrar grande respeito para com ele, abastecê-lo de comida, construir sua casa e fazer canoas. Ao invés de ser o "outro" [grifo do autor] que se incorporou pelo casamento, o novo avô torna-se aquele em torno de quem se une o grupo residencial (Seeger, 1980:3).

Em estudo sobre os macuas, Geffray (2000) identifica uma estrutura de incorporação que expressa, modelarmente, a

romance de Fialho descreve a relação nora-sogra, enquanto Aluisio de Azevedo retrata a representação sobre a sogra na sua relação com o genro.

${ }^{17}$ Para o contexto brasileiro, Koffes (2001) e Fonseca (2000) também analisam a importância de estudar jogos hierárquicos não apenas entre homens e mulheres, mas entre mulheres e entre homens. 
passagem geracional que, na sociedade matrilinear do norte de Moçambique, opera na relação genro-sogra:

[a] mutação realiza-se com a passagem das gerações, isto é, no momento em que a esposa se encontra em situação de casar a sua própria "filha", e de ser colocada, por isso, em uma situação de autonomia que até então a subjugava. Ela própria agora ocupa a posição de "sogra", e goza das prerrogativas do seu novo estatuto. Dirige, por sua vez, as primeiras tentativas de incorporação, pelo casamento, (...), de uma nova geração de "genros", que enfrenta pela primeira vez, e cujo advento geracional finalmente ocasiona o seu (Geffray, 2000:50, grifos do autor).

Inspirada nesses estudos, organizei a estrutura cíclica apresentada. Mas esta estrutura é apenas um modelo, cujos limites são transbordados pelas histórias de casamento. As histórias vividas $e$ narradas pelas mulheres casadas indianas não correspondem à linearidade do ciclo aqui proposto. Nessas histórias, não há uma passagem que vai do esvaziado de poder (pólo nora) para o pleno de poder (pólo sogra). O que pode ser percebido nas histórias de mulheres casadas indianas em Moçambique são jogos que recompõem, permanentemente, as hierarquias familiares.

A partir do anelado de Jagrati, da história de casamento de Kahini e da cerimônia de falecimento da sogra de Laximi pretendi evidenciar aspectos da (re)composição de tradições familiares. Esse material, que destaca a fluidez do domínio da sograria, serve, portanto, para dialogar com as descrições encontradas na literatura sobre a presença de populações de origem indiana na África (Kuper, 1961; Rita-Ferreira, 1984; Prunier, 1990).

Neste artigo, procurei desenvolver o argumento de que os sentidos atribuídos às relações construídas como familiares por pessoas reconhecidas e auto-referenciadas como indianas hindus em Moçambique se reproduzem dinamicamente. Defendi que os laços, aos quais se atribuem sentidos familiares, mesmo entre 
De sogra para nora para sogra

populações indianas, estão em relação com processos de mudança vigentes em Moçambique e em outros contextos com os quais os indianos hindus estabelecem relações (Índia, Portugal $e$ Inglaterra).

A tradição parece, como a Índia, para os indianos em Inhambane: um sítio onde atualiza-se a tradição e participa-se da sua transformação. As viagens à Índia são feitas em nome da manutenção da tradição, mas de cada viagem chegam malas cheias de novidades: novos modelos de sari, padrões novos de tecidos. Casais vão fazer suas cerimônias e, ao mesmo tempo, levam jóias, recebidas em outras cerimônias, para que sejam desmanchadas e refeitas em designs modernos.

Finalmente, ao caracterizar o domínio moral da sograria, pretendi ilustrar a idéia de que para uma mulher casada coabitando ou não com a mãe de seu marido, no mesmo território ou em território (cidade, estado, país) diferente - seu cotidiano doméstico está conectado ao de sua sogra (ou sograria). Enquanto no conceito de Junod a "vukon wana" é o lugar e o laço que une uma mulher ou homem à sua família de aliança, nos casos aqui examinados, o laço não delimita necessariamente um só lugar. $\mathrm{O}$ laço não se desfaz pela migração. Ao contrário, em nome de laços de sograria se amarram os pontos da rede de migração. A rede se altera no tempo e no espaço. O domínio moral da sograria é cultivado num jogo hierárquico flexível.

\section{Referências bibliográficas}

AlenCRASTRO, Luis Felipe. O trato dos viventes. Formação do Brasil no Atlântico Sul. Sec. XVI e XVII. São Paulo, Cia das Letras, 2000.

BASTOS, Suzana. Identidade nacional, ambivalência e fantasma no discurso colonial português sobre os indianos (Moçambique 18931968). Comunicação ao Congresso Internacional sobre Diásporas Indianas, Lisboa, julho, 2003.

; BASTOS, José G. De Moçambique a Portugal: reinterpretações identitárias do hinduísmo em viagem. Lisboa, Fundação Oriente, 2001. 
BATISTA, Elisabeth. Entre o mito e o preconceito: a figura feminina na condição de sogra sob os olhares de Fialho de Almeida e Aluísio Azevedo. Comunicação ao VII Congresso Luso-afro-brasileiro de Ciências Sociais, Coimbra, 16-18 de setembro, 2004.

BESTARD, Joan. Parentesco y modernidad. Buenos Aires, Paidós, 1998.

Bourdieu, P. Le sens pratique. Paris, Minuit, 1980, Cap. "Les usages sociaux de la parenté".

ChiaPin, G.; ARAÚJO, G.; Wagner, A. Sogra-nora: como é a relação entre estas duas mulheres? Psicologia: reflexão e crítica, vol. $11, \mathrm{n}^{\circ}$ 13, Porto Alegre, PUC, 1998.

CuRTIN, Philip D. Bugis, banians and Chinese: Asian traders in the era of the great companies. In: CuRTIN, P. Cross- cultural Trade in World history. Cambridge, Cambridge University, 1986.

DAS, Veena. Fronteiras, violência e o trabalho do tempo: alguns temas wittgensteinianos. Revista Brasileira de Ciências Sociais, vol.14, ${ }^{\circ}$ 40, São Paulo, Anpocs, 1999.

- Critical Events: an Anthropological Perspective on Contemporary India. New York, Oxford University Press, 1995.

DEBERT, Guita Grin. A reinvenção da velhice: socialização e processo de reprivatização do envelhecimento. São Paulo, Edusp/FAPESP, 1999.

. Pressupostos da reflexão antropológica sobre a velhice. In: DEBERT, G. (org.) Antropologia e Velhice, Textos Didáticos, $\mathrm{n}^{\circ} 13$, Campinas-SP, IFCH/UNICAMP, 1998.

Dumont, Louis. Homo Hierarchicus, o sistema de castas e suas implicações. São Paulo, Edusp, 1992.

EliADE, Mircea. O sagrado e o profano. São Paulo, Martins Fontes, 1999.

FORTES, Meyer. Time and Social Structure and Other Essays. London, Athlone, 1970.

FONSECA, Claudia. Família, fofoca e honra: etnografia de relações de gênero e violência em grupos populares. Porto Alegre, UFRGS, 2000.

GALVÃO, Henrique e SELVAGEM, Carlos. Império Ultramarino português. Monografia do Império. IV Volume. Lisboa, Empresa Nacional de Publicidade, 1953.

GefFRAY, Christian. Nem pai, nem mãe. crítica do parentesco, o caso macua. Lisboa, Ndjira, 2000. 
De sogra para nora para sogra

. A causa das armas: Antropologia da guerra contemporânea em Moçambique. Porto, Afrontamento, 1991.

GooDY, Jack. The developmental cycle in domestic groups. Cambridge, Cambridge University Press, 1971, Cap. "The fission of the domestic groups among the Lodagaba".

1998.

. O oriente e o ocidente. (Memórias e Sociedade) Algés, Difel,

Herzfield, M. A antropologia do outro lado do espelho. Difel, São Paulo, 2001.

JARDIM, Marta. Cozinhar, adorar, fazer negócio: um estudo sobre indianos (hindus) em Moçambique. Tese de Doutorado em Ciências Sociais, Universidade Estadual de Campinas, 2006.

JunOT, Henri A. Usos e Costumes dos Bantos. Maputo, Arquivo Histórico de Moçambique, 1996, Cap. "A vida da família".

KOFES, Suely. Mulher, mulheres: identidade, diferença e desigualdade na relação entre patroas e empregadas. Campinas, Editora da UNICAMP, 2001.

KUPER, Hilda. Indian people in Natal. Natal, University Press, 1960.

LEACH, E. R. Sistemas Políticos da Alta Birmânia. São Paulo, Editora da USP, 1996.

Aspects of caste in south India, Ceylon and North-west Pakistan. Cambridge, Cambridge University Press, 1969, Cap. "Introduction: what should we mean by caste?".

MARRIOT, M. Hindu transactions: diversity without dualism. In: Kapferer, B. (ed.) Transactions and meaning. Philadelfia, 1976.

MAYBURY-LewIS, B. A sociedade xavante. Rio de Janeiro, Francisco Alves, 1984.

NEWITT, Malyn. História de Moçambique. Lisboa, Europa América, 1997.

PATEL, Vikran; RodRIGUEZ, Merlyn; SouZA, Nadita de. Gender, poverty and postnatal depression: a study of mother in Goa, Índia. The American Journal of Psychiatry, $\mathrm{n}^{\circ}$ 159, American Psychiatric Association, janeiro de 2002 (http://www.ajp.psychiatryonline.org/cgi/ content/full/159/1/43).

PÉLISSIER, René. História de Moçambique: formação e oposição (1854 1918). 2 vols. Estampa, Lisboa, 1994. 
PereIRA LeITE, Joana. Diáspora indiana em Moçambique. Economia Global e Gestão, n 2, Lisboa, AEDG/ISCPE, 1996.

PEREZ, Rosa M. Reis e intocáveis: um estudo do sistema de castas no noroeste da Índia. Oeiras, Celta, 1994.

PINA CABRAL, João. O homem na família, cinco ensaios de antropologia. Lisboa, ICS, 2003, Cap. "A pessoa familiar".

PRUNIER, Gerard. L'Ouganda et la question indienne (1896 - 1972). Paris, Recherche sur les civilizations, 1990.

RAHEJA, Glória G. The poison in the Gift Ritual Prestation and Dominant caste in a North Indian Village. Chicago, The University of Chicago, 1998.

RITA-FERREIRA, Antônio. Moçambique e os naturais da Índia Portuguesa. II Seminário Internacional de História Portuguesa, Actas, Lisboa, CDU, 1985.

SEEGER, Anthony. Os índios e nós: estudo sobre sociedades tribais brasileiras. Rio de Janeiro, Campus, 1980, Cap. "Os velhos nas sociedades tribais".

SHAH, A. M. The family in India: critical essays. Hyderabad, Orient Longman, 1998.

SRINIVAS, M. N. Caste in modern India and other essays. London, Asia, 1970.

TEIXEIRA, Cândido. Inhambane: o museu regional $e$ a comunidade hindu. V Encontro de museus de países e comunidades de língua portuguesa, Maputo, 2000.

THOMAZ, Omar R. Entre inimigos e traidores: suspeitas e acusações no processo de formação nacional no Sul de Moçambique. Travessias, vols. 4/5, Lisboa, ICS, 2004.

Forasteiros e Nativos: A construção social da autoctonia e a excepcionalização da territorialidade. Indianos em Moçambique e Mulatos no Haiti. Projeto de Pesquisa, Cebrap, São Paulo, 2001.

Velkoff, Victoria A.; Adlakha, Arjun. Women's health in Índia. (Women of the World, The official statistics). US. Department of Commerce Economics and Statistics Administration, Bureau of the census, 1998.

VerTOVEC, S. The hindu diaspora. Comparative patterns. Londres/Nova York, Routledge, 2000. 
De sogra para nora para sogra

WEBER, Max Ensaios sobre sociologia da religião. 2 vols. Espanha, Taurus, 1987 [1921].

ZAMPARONI, Valdemir. Entre narros e mulungos: colonialismo e paisagem social em Lourenço Marques c. 1890-1940. Tese de Doutorado em História Social, São Paulo, FFLCH/USP, 1998. 